AESEARCH PAPER

\title{
Ethical values in caring encounters on a
geriatric ward from the next of kin's perspective: \\ Ethical values in caring encounters on a
geriatric ward from the next of kin's perspective: An interview study
}

Lise-Lotte Jonasson RN BSc MSc

Lecturer, Department of Nursing Science, School of Health Sciences, University of Jönköping, Jönköping, Sweden and Lecturer, Department of Medical and Health Sciences, Division of Nursing Science, Faculty of Health Sciences, Linköping University, Linköping, Sweden

Per-Erik Liss PhD

Professor, Department of Health and Society, Linköping University, Linköping, Sweden

Björn Westerlind PhD MD

Chief Physician, Geriatric Clinic, County Hospital Ryhov, Jönköping, Sweden

Carina Berterö RN BSc MScN PhD

Associate Professor, Department of Medical and Health Sciences, Division of Nursing Science, Faculty of Health Sciences, Linköping University, Linköping, Sweden

Accepted for publication August 2009

Jonasson L-L, Liss P-E, Westerlind B, Berterö C. International Journal of Nursing Practice 2010; 16: 20-26 Ethical values in caring encounters on a geriatric ward from the next of kin's perspective: An interview study

The aim of this study was to identify and describe the governing ethical values that next of kin experience in interaction with nurses who care for elderly patients at a geriatric clinic. Interviews with 14 next of kin were conducted and data were analysed by constant comparative analysis. Four categories were identified: receiving, showing respect, facilitating participation and showing professionalism. These categories formed the basis of the core category: 'Being amenable', a concept identified in the next of kin's description of the ethical values that they and the elderly patients perceive in the caring encounter. Being amenable means that the nurses are guided by ethical values; taking into account the elderly patient and the next of kin. Nurses' focusing on elderly patients' well-being as a final criterion affects the next of kin and their experience of this fundamental condition for high-quality care seems to be fulfilled.

Key words: ethical values, geriatric wards, grounded theory, next of kin, nursing ethics.

Correspondence: Lise-Lotte Jonasson, Department of Nursing Science, School of Health Sciences, University of Jönköping, SE-551 11 Jönköping, Sweden. Email: lise-lotte.jonasson@hhj.hj.se

\section{INTRODUCTION}

All persons have the same worth but the patient who is in the greatest need of care will be the first priority. Hence, patients and next of kin should be perceived with respect, integrity and the possibility of participating in the care given. ${ }^{1}$ 
The foundation of general broad indications, focusing on actions and conduct, serves as a guideline for how health-care workers should act towards patients and their next of kin when they are confronted with ethical problems. ${ }^{2}$ A next of kin is a person who has a near relation to the elderly patients, that is, a friend; it could also be a person related by blood.,

In previous studies, it has been stated that the patients and their next of kin are seen as a team in the caring encounter and it is important to confirm the experiences of both patients and next of kin in this encounter; the next of kin might function as a bridge between the nurse and the patient in some situations. ${ }^{5,6}$ The nurse's verbal and non-verbal methods of communication correspond to some or all aspects of the immediate reaction. ${ }^{7}$ It would appear from other studies that the next of kin felt that they were not equal to the nurses in the caring encounter and these experiences are closely related to the nurse's conceptions, opinions and values. How they act is thus an important aspect to consider when examining the quality in caring encounters. ${ }^{8,9}$ It can also be the next of kin's feelings that the nurses have difficulties. ${ }^{10}$ When a family member is ill and cared for in hospital, the roles, routines and communication of the family members might change. The next of kin's positive well-being affects the patients' health positively. ${ }^{11-14}$

The next of kin and health-care professionals might have different values and objectives for the patient and the next of kin might feel excluded from the decision-making process. They are observant for signs of misery and if they are not able to receive a clear diagnosis concerning their elderly person, their frustration will increase. Supportive nurses who involve the next of kin and taking them seriously might relieve these feelings. ${ }^{15}$ The nurses are in a unique position to work with the family as a partner, providing quality care for the elderly patients during hospitalization $^{15,16}$ and an important component in order for the next of kin to feel satisfied with their interaction with nurses. ${ }^{17}$

Ethical values are the backbone of how we act, behave and deal with different moral situations. ${ }^{18}$ The ethical issues of autonomy, beneficence, non-maleficence and justice are central components of nursing and health-care ethics. ${ }^{19}$ These statements are a kind of personal ethics; this depends on the person's upbringing and the environmental atmosphere in a caring situation. ${ }^{19}$ The nurse's attitude, values, self-respect, etc. influence the choice of care plan. ${ }^{20}$ Central is noticing the ethical values the nurses have in the caring encounter. It is also important to focus on the interaction between the nurse, the elderly patient and the next of kin; this helps other persons to understand what is happening in the caring encounter. ${ }^{7,21,22}$

\section{Aim}

The aim of this study was to identify and describe the governing ethical values that next of kin experience in interaction with nurses who care for elderly patients at a geriatric clinic.

\section{METHOD}

A qualitative approach was used for the study, as we wished to understand human behaviour. Symbolic interaction is an ensemble between people and the social aspects of real life. Important components are gestures, attitudes and the act of controlling the attitude interacted between people. ${ }^{23}$ Thus, grounded theory (GT) method has been used, discovering and developing concepts starting from collection and analysis of data in a constant, systematic and comparative way. ${ }^{24}$ The next of kin describe the nurse's behaviour in caring encounters with the elderly patient. This behaviour makes the ethical values visible. ${ }^{25}$

\section{Setting and participants}

The study was performed at a geriatric clinic, and 'elderly patients' in this context defines people $>65$ years old, with different needs of care. ${ }^{26}$ The average caring time for the elderly patients was 18 days and, after discharge, they went home or to another caring facility. In many instances, the age for retirement from employment is used to define an older person. ${ }^{27-30}$ The definition of an elderly or older person in most developed countries is usually $\geq 65$ years. $^{27}$

Information about the study was given to the manager of the clinic, the director of the department and the personnel department; all approved the study. A nurse at the geriatric clinic gave 19 elderly persons and their next of kin verbal and written information about the study and that participation was voluntary. Fourteen next of kin agreed to participate. Consideration has been given to the Declaration of Helsinki and standard procedures were followed for participant-informed consent and confidentiality (law 2003:460). Approval was also received from the Local Research Ethics Committee 'Dnr'.170-06. 
The next of kin were of varying age (40-80 years), median 55 years. They had different occupations, visiting the clinic to varying degrees. Even the interest in participating in caring for their elderly person and decisionmaking varied.

\section{Interviews}

Data were collected between November 2006 and September 2007. The next of kin chose the place and time convenient for them: three interviews at the hospital and 11 in their own homes.

An interview guide was used, which gave the interviewer the freedom to have a conversation with the interviewee on a specific topic concerning caring. ${ }^{31}$ The interviewer was free to explore and ask questions on the basis of an interview guide that explained the topic under study $^{31,32}$

The informants expressed, in their own words, their experiences and contributed their perspectives regarding the caring encounter. The interviews lasted up to $90 \mathrm{~min}$, were tape-recorded and transcribed verbatim. After 13 interviews, saturation was reached. Another interview was performed for the purpose of confirmation, in order to secure saturation. ${ }^{23}$

\section{Data analysis}

The transcribed text was analysed with constant comparative analysis. ${ }^{24,33}$ The analysis began by openly encoding the first interview. The aim was to capture the substance in the data and then to break it down into identifiable substantive codes. The different codes generated from the different interviews were compared. The codes were labelled with origin words from the data. ${ }^{23,33}$

The analysis continued, with the aim of reaching a higher level of abstraction of the material and categories were thus identified. The categories were labelled with more abstract concepts. Obtaining data and analysis continued until a 'saturation point' had been reached; in other words, nothing new emerged in the analysis. The final level was to identify a theoretical construction - a core category - that answers questions and explains the ethical values under study. This construct adds theoretical meaning and scope to the substantive theory and could be implicitly found in all data. ${ }^{23,33}$

\section{RESULTS}

Four categories were identified: receiving, showing respect, facilitating participation and showing profession-

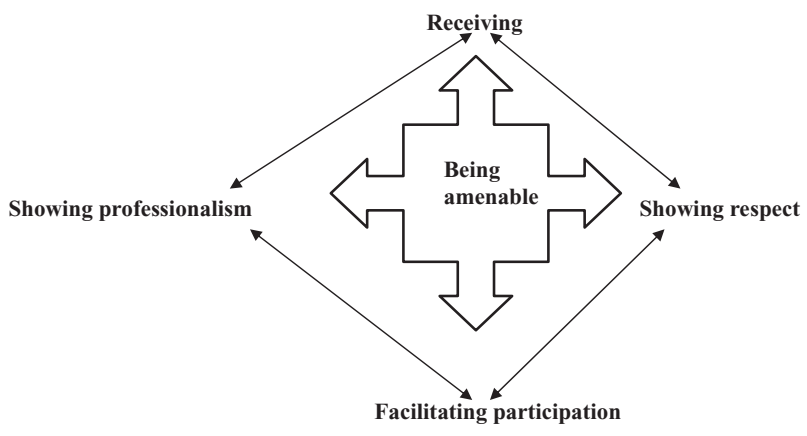

Figure 1. The four categories: receiving, showing respect, facilitating participation and showing professionalism, are related to and affect each other. These categories generate the core category 'Being amenable'.

alism. All the categories were related to and thus affect each other; thereby, the categories could sometimes seem interrelated and repetitive, generating the core category. The core category was identified as 'Being amenable', which provides the explanation of how the next of kin described the ethical values experienced through nurses caring for elderly patients at a geriatric clinic (Figure 1).

\section{Receiving}

Nurses' ethical values were embodied in the caring encounter by them receiving the next of kin with nearness or distance. Nearness was when they were welcoming and inviting towards the next of kin and had a friendly attitude. The nurses' ethical values affected their manner: presenting themselves, appearing friendly and attentive towards the elderly patients. This affected the next of kin positively in the caring encounter. They experienced a positive atmosphere on the ward, when they were given the possibility of coming to the ward at times suitable for them.

The receiving could also be conducted with distance. This was apparent when the nurses showed that they did not trust the next of kin. Distance could also be experienced when the next of kin noticed that the nurses were against them in their opinion, shown by an uninviting, almost frozen attitude. Distance or negative receiving was when the nurses were not attentive towards the elderly.

\section{Showing respect}

Showing respect is a concept that has both a front-side (respect) and a back-side (disrespect). Respect was shown by body language and by verbal language. Showing respect 
through body language appeared in the nurses' actions. The nurses were then perceived as being respectful and caring. By listening with interest to the next of kin, the nurses allowed them to take part. Verbally the nurses showed respect by talking to the next of kin in a proper way and by asking questions to achieve a deeper understanding of the elderly patient and their next of kin. Showing respect was a caring act, presenting the ethical values that could be seen more obviously in special situations such as when the nurses were busy.

Disrespect was shown when the nurses showed that they did not trust either the elderly patient or the next of kin. Being ignored was to be disrespectfully treated. Not giving clear information was also disrespectful, for example, the nurse causing misunderstanding by using difficult words or medical terms, or asking clumsy questions that might be experienced as insulting. Ignorant behaviour was when information passes from one nurse to another, there were long waits without any explanation, or when the nurses were not flexible in their actions not trying to find solutions.

\section{Facilitating participation}

The basis for participation was provided when the nurses involved the next of kin in the caring encounter, when they were invited through receiving understandable and clear information. This acknowledgement promoted collaboration between the elderly patient, the next of kin and the nurse: they were equally valued in the situation. The next of kin could easily participate in small everyday activities. If the next of kin felt that the focus was on the elderly person, that the nurses were acting in his/her best interests and that they, as next of kin, were invited to participate and were well informed, then they experienced that they could participate better. The next of kin could also be an important source of information regarding the elderly patient. The caring situation was an important and perhaps unusual one for the next of kin but a common event for the nurses as caring professionals, so there was a need for sensitivity and 'long-term planning' . The elderly patients, as well as the next of kin, need to prepare themselves, so inviting them at the last minute to, for example, a caring meeting hinders rather than facilitates their participation.

\section{Showing professionalism}

Nurses were seen to be professional by the next of kin; they were competent and possessed knowledge in caring that was both theoretical and practical and they were willing to perform their duties. The nurses' empathy and attitude provided a guarantee that the caring encounter would be good and their encouragement and responsible attitude led to the next of kin feeling supported and secure.

\section{The core: Being amenable}

Being amenable is about being there for others. The nurses met the elderly patient/next of kin through receiving them with nearness; they invited the next of kin through their attitude, how they approached them. This provides the basis for respect between the people in the caring encounter. Being valued and acknowledged opens up the possibility of participating and being an active part in the caring encounter. The nurses had authority in the caring encounter and could show their professionalism; that is, they were competent and guided by the ethical principle that all people have equal value. The nurses focused on the elderly patient's well-being as a final criterion of good ethical care; this influenced the next of kin and their experiences of this fundamental condition for high-quality care seemed to be fulfilled.

Being amenable shows the ethical values in the nurse's behaviour and how the nurses act in caring encounters. The next of kin were satisfied when the nurses were sensitive regarding the elderly patient's well-being, and that the nurses 'are there', both physical and mentally through their behaviour and actions.

\section{DISCUSSION}

The nurses are expected to 'be amenable' and the analysis in the present study has built up this concept in the setting of the next of kin's descriptions of the ethical values the elderly patients perceive in the caring encounter. Being amenable, as identified and described here, is quite unique: within an ethical perspective and relating to different concepts. Accessible is a synonym that is often connected with time. ${ }^{34}$ Being amenable could, with some broad interpretation and good will, be found in other articles as concepts such as support, behaviour and interaction with the nurses. ${ }^{18,36-39}$ None of these articles has, however, highlighted the links between: receiving, showing respect, facilitating participation and showing professionalism in connection with the core category of being amenable identified here.

Being amenable implies that the nurses invite the elderly patients and their next of kin into the caring 
encounter. In this way, they can take an active part in tasks, as well as in decision-making. The next of kin perhaps do not feel excluded from the decision-making process, as in a previous study. ${ }^{15}$

The next of kin are perceptive when the nurses distance the elderly patients, leading to the next of kin believing that the nurses are ignoring them, as in other studies. ${ }^{35,37}$ When the nurses are amenable, they are welcoming and inviting and their attitude shows respect. These form the basis of trust from the next of kin's perspective. Not being amenable is when the next of kin perceive the nurses do not cooperate and communicate. Such behaviour sends signals to the next of kin and they perceive less value in the caring encounter, as in another study. ${ }^{35}$

Good care quality is recognized by the next of kin as involving the opportunity to attend the ward at times suitable for them and this finding is in agreement with another study. ${ }^{38}$ There must be an atmosphere of respect and openness on the part of the nurses, which in turn allows the next of kin to express themselves and ask questions. How the next of kin perceive the atmosphere is related to and depends on the ethical values shown in the personnel group, that is, whether or not they are being amenable. ${ }^{19}$

In our study, the next of kin noticed that the nurses showed respect and were amenable, even when there was a stressful situation on the ward. In a mutual interaction, the next of kin were also aware of the nurses' stress. The opposite could be found in other studies. ${ }^{6,38}$

Being amenable might also confirm the nurses' competence: doing the right thing at the right moment. This finding is in agreement with another study. ${ }^{35}$ Being amenable is about, as a nurse, being sensitive to what the elderly patient, as well as the next of kin, has to say. This provides the basis of a partnership between the elderly patients, the next of kin and the nurses, as in other studies. ${ }^{6,37,38,40}$ Being amenable helps us to understand what is happening in the caring encounter. ${ }^{21,22}$

If the nurses focus on the value of the elderly patient's autonomy and beneficence, ${ }^{19}$ as well as being sensitive towards and treating the next of kin as a part of the team with the elderly in the caring encounter, ${ }^{9-12}$ the participation of the next of kin will be realized.

Validity in GT should be judged by fit, relevance, workability and modifiability. ${ }^{24,33,41}$ A GT has codes that fit the data and reality from which they are derived, and in this study the codes are derived from the data. Fit has to do with how closely concepts fit with the incidents they represent, and this is related to how thoroughly the constant comparison of incidents to concepts was performed. Workability is about the concepts working and being able to explain the major processes of behaviour of the substance area. We think that the findings of this study have workability, as they provide an explanation of the ethical values shown. The concepts must be relevant to the core category and its ability to explain what is going on in a caring encounter. If the participants recognize the construct, there will be relevance..$^{23,24,33}$ These findings have been presented for some of the next of kin and the construct was recognized. A modifiable theory can be altered when new relevant data are compared with existing data; that is, the theory has modifiability. ${ }^{33}$ The strength of GT is that it is a very systematic method, in both data collection and analysis. If this systematic approach is followed, there will be trustworthiness of the data.

In conclusion, the nurse's behaviour and actions make the ethical values visible for the next of kin. When the nurses are focused on elderly patients' well-being as a final criterion of good ethical care, they are 'being amenable'. It is necessary that all nurses are attentive to the observation that being amenable is of great significance for how the next of kin will experience the caring encounter. In the interaction between the nurse and the elderly patients, it will influence the next of kin and their experience of this fundamental condition for high-quality care seems to be fulfilled. If the nurses' behaviour and actions are according to ethical values, that is, they are receiving, showing respect, inviting to participate and showing professionalism, then the next of kin will feel they are important; they are of value and are allowed interaction on equal terms.

\section{REFERENCES}

1 Hälso-och sjukvårdslag (SFS 1982:763). Stockholm. Available from URL: http://www.notisum.se/rnp/sls/LAG/ 19820763.htm. Accessed 17 February 2009.

2 Wright LM, Watson WL, Bell BM. Familjefokuserad omvårdnad. Lund, Sweden: Studentlitteratur, 2002.

3 National Board of Health and Welfare. (Socialstyrelsen). Närstående. Available from URL: http://www. socialstyrelsen.se/Termbank/. Accessed 3 January 2010.

4 National Board of Health and Welfare. (Socialstyrelsen). Anhörig. Available from URL: http://www. socialstyrelsen.se/Termbank/. Accessed 3 January 2010.

5 Åstedt-Kurki P, Paavilainen E, Tammentie T, PaunonenIlmonen $M$. Interaction between adult patients' family members and nursing staff on a hospital ward. Scandinavian Journal of Caring Sciences 2001; 15: 142-150. 
6 Brobäck G, Berterö C. How next of kin experience palliative care of next of kin at home. European Journal of Cancer Care 2003; 12: 339-346.

7 Blumer H. Symbolic Interactionism Perspective and Method. Los Angeles, CA, USA: University of California Press, 1969.

8 SOU 1998:16. När åsikter blir handling-en kunskapsöversikt om bemötande av personer med funktionshinder. Regeringskansliet, Stockholm, 1998.

9 Wright LM, Leahey M. Maximizing time, minimizing suffering: The 15 minute (or less) family interview. Journal of Family Nursing 1999; 5: 259-274.

10 Vårdalstiftelsen. Etik i vården Frågor för forskning. Stockholm: Vårdalstiftelsen, 1999.

11 Rutledge DN, Donaldsson NE, Pravikoff DS. Caring for families of patients in acute or chronic health settings: Part 1-Principles. The Online Journal of Clinical Innovations 2000. Available from URL: http://www.cinahl.com or from Cinahl Informations Systems, 1509 Wilson Terrace, Glendale, CA 91206, USA.

12 Lindharth T, Bolmsjö IA, Rahm Hallberg I. Standing guard - Being a next of kin to a hospitalised, elderly person. Journal of Aging Studies 2006; 20: 133-149.

13 Li H, Stewart BJ, Imle MA, Archbold PG, Felver L. Families and hospitalized elders. A typology of family care actions. Research in Nursing and Health 2000; 23: 316.

14 Laitinen P, Isola A. Promoting participation of informal caregivers in the hospital care of the elderly patient. Informal caregivers perceptions. Journal of Advanced Nursing 1996; 23: 942-947.

$15 \mathrm{Li} \mathrm{H}$. Identifying family care process themes in caring for their hospitalized elder. Applied Nursing Research 2005; 18: 97-101.

16 Li H. Family caregivers' preferences in caring for their hospitalized elderly next of kin. Geriatric Nursing 2002; 23: 204-207.

17 Hertzberg A, Ekman S-L. 'We not them and us?' Views on the relationships and interactions between staff and relatives of older people permanently living in nursing homes. Journal of Advanced Nursing 2008; 31: 614 622.

18 Kälvemark S, Höglund AT, Hansson MG, Westerholm P, Arnetz B. Living with conflicts - Ethical dilemmas and moral distress in the health care system. Social Science and Medicine 2003; 58: 1075-1084.

19 Edwards SD. Nursing Ethics, A Principle-Based Approach. London: Macmillan, 2002.

20 Gustafsson B, Parfitt B. Views of humanity and nursing practice. An analysis of nursing: A Christian/diaconal, a historical/medical and a humanistic/SAUC model. Ethics and Medicine 2002; 18: 159-170.

21 Orlando IJ. The Dynamic Nurse-Patient Relationship, Function, Process and Principles. New York, NY, USA: G P Putam, 1961.
22 Orlando IJ. The Discipline and Teaching of Nursing Process: An Evaluative Study. New York, NY, USA: G P Putam, 1972.

23 Glaser BG, Strauss AL. The Discovery of Grounded Theory: Strategies for Qualitative Research. New York, NY, USA: Aldine De Gruyter, 1967.

24 Glaser BG. Basics of Grounded Theory Analysis. Mill Valley, CA, USA: The Sociology Press, 1992.

25 Dierckx de Casterlé B, Grypdonck M, Cannaerts N, Steeman E. Empirical ethics in action: Lessons from two empirical studies in nursing ethics. Medicine, Health Care and Philosophy 2004; 7: 31-39.

26 Encyclopedia. Definition of 'geriatrics'. 2009. Available from URL: http://www.encyclopedia.com/topic/ geriatrics.aspx. Accessed 3 January 2010.

27 WHO. 2008. Definition of older person. Available from URL: http://www.who.int/healthinfo/survey/ ageingdefnolder/en/index.html. Accessed 22 July 2008.

28 Chris G. Aging and old age in medieval society and the transition of modernity. Journal of Aging and Identity 2002; 7: 25-41.

29 Government Offices of Sweden (SOU: 2003:91) (Regeringskansliet). Äldrepolitik för framtiden. 100 steg till trygghet och utveckling med en åldrande befolkning. Available from URL: http://www.regeringen.se/content/1/c4/26/11/ b51e808d.pdf. Accessed 3 January 2010.

30 Roebuck J. When does old age begin? The evolution of the English definition. Journal of Social History 1979; 12: 416428.

31 Patton MQ. Qualitative Research \& Evaluation Methods. Thousand Oaks, CA, USA: Sage, 2002.

32 Berg L. Qualitative Research Methods for the Social Science. Boston, MA, USA: Allyn and Bacon, 1995.

33 Glaser BG. Theoretical Sensitivity: Advances in the Methodology of Grounded Theory. Mill Valley, CA, USA: Sociology Press, 1978.

34 Swedish Association of Local Authorities and Regions (Sveriges Kommuner och Landsting -SKL). Vardbarometern, Befolkningens syn på vården. 2006. Rapport 1, 2007.

35 Atree M. Patients and next of kin experiences and perspectives of 'Good' and 'Not so good' quality care. Journal of Advanced Nursing 2001; 33: 456-466.

36 Eriksson E, Lauri S. Informal and emotional support for cancer patient's next of kin. European Journal of Cancer Care 2000; 9: 8-15.

37 Hertzberg A, Ekman S-L, Axelsson K. Staff activities and behavior are source of many feelings: Next of kin interactions and relationships with staff in nursing homes. Journal of Clinical Nursing 2001; 10: 380-388.

38 Al-Hassan M, Hweidi I. The perceived needs of Jordanien families of hospitalized, critically ill patients. International of Journal of Practical Nursing 2004; 10: 64-71.

39 Van Der Smagt-Duijnstee ME, Hamers JPH, Abu-Saad $\mathrm{HH}$, Zuidhof A. Next of kin of hospitalized stroke 
patients; their needs of information, counseling and accessibility. Journal of Advanced Nursing 2001; 33: 307315.

40 Heyland D, Rocker D, Dodek P et al. Family satisfaction in the intensive care unit: Results of a multicenter study. Critical Care Medicine 2002; 30: 1413-1418.
41 Jeanne QB. Grounded theory and nursing knowledge. Qualitative Health Research 1996; 6: 406-428. 